Case Report

\title{
Circulatory Support with Venoarterial ECMO Unsuccessful in Aiding Endogenous Diltiazem Clearance after Overdose
}

\author{
Erin N. Frazee, ${ }^{1}$ Sarah J. Lee, ${ }^{2}$ Ejaaz A. Kalimullah, ${ }^{3}$ \\ Heather A. Personett, ${ }^{1}$ and Darlene R. Nelson ${ }^{2}$ \\ ${ }^{1}$ Hospital Pharmacy Services, Mayo Clinic, 200 1st SW, Rochester, MN 55905, USA \\ ${ }^{2}$ Division of Pulmonary and Critical Care Medicine, Mayo Clinic, 200 1st SW, Rochester, MN 55905, USA \\ ${ }^{3}$ Department of Emergency Medicine and Division of Pulmonary and Critical Care Medicine, Loyola University Medical Center, \\ 2160 S 1st Avenue, Maywood, IL 60153, USA
}

Correspondence should be addressed to Erin N. Frazee; frazee.erin@mayo.edu

Received 6 June 2014; Accepted 29 July 2014; Published 17 August 2014

Academic Editor: Moritoki Egi

Copyright (c) 2014 Erin N. Frazee et al. This is an open access article distributed under the Creative Commons Attribution License, which permits unrestricted use, distribution, and reproduction in any medium, provided the original work is properly cited.

Introduction. In cardiovascular collapse from diltiazem poisoning, extracorporeal membrane oxygenation (ECMO) may offer circulatory support sufficient to preserve endogenous hepatic drug clearance. Little is known about patient outcomes and diltiazem toxicokinetics in this setting. Case Report. A 36-year-old woman with a history of myocardial bridging syndrome presented with chest pain for which she self-medicated with $2.4 \mathrm{~g}$ of sustained release diltiazem over the course of 8 hours. Hemodynamics and mentation were satisfactory on presentation, but precipitously deteriorated after ICU transfer. She was given fluids, calcium, vasopressors, glucagon, high-dose insulin, and lipid emulsion. Due to circulatory collapse and multiorgan failure including ischemic hepatopathy, she underwent transvenous pacing and emergent initiation of venoarterial ECMO. The peak diltiazem level was $13150 \mathrm{ng} / \mathrm{mL}$ (normal 100-200 ng/mL) and it remained elevated at $6340 \mathrm{ng} / \mathrm{mL}$ at hour 90 . Unfortunately, the patient developed multiple complications which resulted in her death on ICU day 9. Conclusion. This case describes the unsuccessful use of ECMO for diltiazem intoxication. Although past reports suggest that support with ECMO may facilitate endogenous diltiazem clearance, it may be dependent on preserved hepatic function at the time of cannulation, a factor not present in this case.

\section{Introduction}

The American Association of Poison Control Centers reported more than 100,000 cardiovascular medication poisonings in 2011, of which calcium channel blocker (CCB) overdoses were involved in approximately $60 \%$ of the fatal events [1]. In both mono- and mixed-exposures of CCBs, diltiazem, a lipophilic, protein-bound, hepatically cleared, nondihydropyridine $\mathrm{CCB}$, carried a significant risk of fatality [2].

Supportive care remains the cornerstone of diltiazem overdose management. Targeted therapies include calcium, high-dose insulin euglycemia, glucagon, lipid emulsion, and cardiac pacing [3]. Enhanced elimination by hemodialysis, hemoperfusion, albumin dialysis, and plasma exchange variably impacts clinical outcomes [3-6]. Because of the inconsistent results of extracorporeal drug removal, there is instead an interest in preservation of endogenous drug clearance mechanisms (i.e., hepatic metabolism) through extracorporeal membrane oxygenation (ECMO-) mediated circulatory support. Little is known about the impact of ECMO on patient outcomes and diltiazem toxicokinetics in this setting.

Herein, we present an unsuccessful case of ECMO use for diltiazem overdose and review the existing literature on circulatory support for nondihydropyridine CCB poisonings.

\section{Case Report}

A 36-year-old, $68 \mathrm{~kg}$, woman with a history of myocardial bridging syndrome and an unroofing procedure two years prior to admission presented with a two-day history of chest pain for which she self-medicated with 2.4 grams of sustained release (SR) diltiazem over the course of 8 
TABLE 1: Vital signs and laboratory measures and events during the admission.

\begin{tabular}{|c|c|c|c|}
\hline $\begin{array}{l}\text { Hours and days } \\
\text { after ingestion }\end{array}$ & $\begin{array}{l}\text { Vitals signs and } \\
\text { pertinent laboratory values }\end{array}$ & Events and interventions & $\begin{array}{c}\text { Diltiazem } \\
\text { level }(\mathrm{ng} / \mathrm{mL})\end{array}$ \\
\hline $\begin{array}{l}8 \text { hours } \\
\text { (presentation) }\end{array}$ & $\begin{array}{l}\text { Vitals: HR } 77 \text { bpm, BP 102/56 mmHg } \\
\text { (MAP 71) }\end{array}$ & $\begin{array}{l}\text { Calcium, glucagon, high-dose insulin, fluids, } \\
\text { lipid emulsion, and vasopressors started }\end{array}$ & - \\
\hline 19 hours & 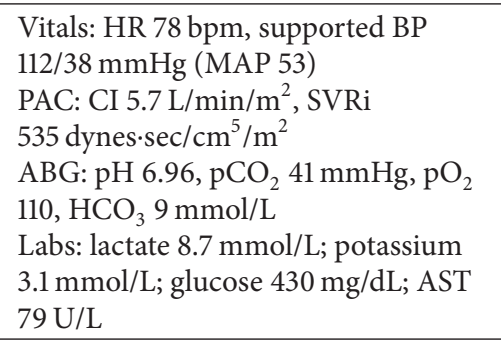 & $\begin{array}{l}\text { PAC placed, transvenously paced at } 80 \mathrm{bpm} \\
\text { due to interval development of prolonged sinus } \\
\text { pauses; methylene blue attempted; CVVH } \\
\text { begun }\end{array}$ & - \\
\hline 23 hours & - & - & 1140 \\
\hline 25 hours & $\begin{array}{l}\text { Immediately before ECMO } \\
\text { cannulation: } \\
\text { Vitals: HR } 96 \mathrm{bpm} \text { (paced), supported } \\
\text { BP } 93 / 48 \mathrm{mmHg} \text { (MAP } 63 \text { ) } \\
\text { PAC: CI } 4.1 \mathrm{~L} / \mathrm{min}^{5} \mathrm{~m}^{2}, \text { SVRi } \\
804 \text { dynes } \cdot \mathrm{sec} / \mathrm{cm}^{5} / \mathrm{m}^{2} \\
\text { Labs: lactate }>12.2 \mathrm{mmol} / \mathrm{L} \text {; potassium } \\
2.2 \mathrm{mmol} / \mathrm{L} ; \text { AST } 3112 \mathrm{U} / \mathrm{L} \text {, INR } 2.4\end{array}$ & $\begin{array}{l}\text { V-A ECMO cannulation, total circuit flow } \\
4.8-5.1 \mathrm{~L} / \mathrm{min}\left(\text { ECMO CI } 2.9-3.1 \mathrm{~L} / \mathrm{min} / \mathrm{m}^{2}\right)\end{array}$ & - \\
\hline 39 hours & - & - & 9450 \\
\hline 44 hours & - & - & 7120 \\
\hline 51 hours & $\begin{array}{l}\text { Hemodynamics: HR } 100 \text { (paced; } \\
\text { asystolic when pacemaker is off), total } \\
\text { ECMO circuit flow } 4.6 \mathrm{~L} / \mathrm{min} \text { (ECMO } \\
\text { CI } 2.7 \mathrm{~L} / \mathrm{min} / \mathrm{m}^{2} \text { ) } \\
\text { Labs: lactate }>18 \mathrm{mmol} / \mathrm{L} \text {; potassium } \\
4.9 \mathrm{mmol} / \mathrm{L}\end{array}$ & $\begin{array}{l}\text { Abdominal compartment syndrome, to } \\
\text { operating room for exploration, evacuation of } \\
\text { ascites, and temporary closure }\end{array}$ & 13150 \\
\hline 71 hours & $\begin{array}{l}\text { Labs: lactate } 15.4 \mathrm{mmol} / \mathrm{L} \text {; potassium } \\
8.1 \mathrm{mmol} / \mathrm{L} \text {; aPTT } 63 \text { seconds } \\
\text { (heparinized), INR } 2.3 \\
\text { TTE: LV EF } 10-15 \% \text { and a severe } \\
\text { decrease in right ventricular systolic } \\
\text { function; no evidence of tamponade }\end{array}$ & $\begin{array}{l}\text { Persistent elevation in potassium and lactate } \\
\text { with increasing abdominal distension; } \\
\text { prompted exploration where ischemic small } \\
\text { bowel and colon were found along with a large } \\
\text { retroperitoneal hematoma; resected and left in } \\
\text { discontinuity }\end{array}$ & 2020 \\
\hline 90 hours & - & $\begin{array}{l}\text { Developed bilateral lower-extremity } \\
\text { compartment syndrome requiring fasciotomies }\end{array}$ & 6340 \\
\hline Day 5 & - & $\begin{array}{l}\text { Underwent abdominal reexploration with } \\
\text { creation of an end ileostomy and } 3 \text { mucous } \\
\text { fistulae }\end{array}$ & - \\
\hline Day 7 & - & $\begin{array}{l}\text { Regained sinus rhythm and downtitrated } \\
\text { vasopressors; unable to wean from ECMO }\end{array}$ & - \\
\hline Day 8 & - & $\begin{array}{l}\text { Developed a GI bleed in the setting of } \\
\text { refractory thrombocytopenia, anticoagulation } \\
\text { for ECMO, and autoanticoagulation from acute } \\
\text { liver injury }\end{array}$ & - \\
\hline Day 9 & - & Transitioned to comfort cares and died & - \\
\hline
\end{tabular}

hours. Neither subjective nor objective evidence suggested coingestion. On arrival to the ED, she was mentating appropriately, with a blood pressure (BP) of 102/56 $\mathrm{mm} \mathrm{Hg}$ and a pulse of 77 beats per minute (bpm) in sinus rhythm (Table 1). She became hypotensive (BP $88 / 40 \mathrm{~mm} \mathrm{Hg}$ ) and was administered intravenous (IV) fluids, $5 \mathrm{mg}$ IV glucagon and $3 \mathrm{~g}$ of IV calcium gluconate. Hypotension persisted; therefore, a norepinephrine infusion was started. Highdose insulin (1 unit $/ \mathrm{kg} / \mathrm{hr}$ insulin) and a $1.5 \mathrm{~mL} / \mathrm{kg}$ bolus of lipid emulsion (20\% Intralipid) were subsequently given 
and continued in the ICU (insulin titrated to 10 units $/ \mathrm{kg} / \mathrm{hr}$ within 5 hours of ICU admission; Intralipid infused at $0.5 \mathrm{~mL} / \mathrm{kg} / \mathrm{hr}$ ) [7]. At admission to the ICU, she was alert and oriented although increasingly dyspneic. Activated charcoal and gastric lavage were not used given the elapsed time between ingestion and presentation, the patient's nausea and concerns about the risk of aspiration, and her suspected ileus with high vasopressor requirements. Despite escalating norepinephrine doses to $2 \mathrm{mcg} / \mathrm{kg} / \mathrm{min}$, with the addition of $1 \mathrm{mcg} / \mathrm{kg} / \mathrm{min}$ epinephrine, vasopressin at $0.1 \mathrm{units} / \mathrm{min}$, calcium chloride boluses and infusion, and $75 \mathrm{mcg} / \mathrm{kg} / \mathrm{hr}$ (5 mg/hr) of glucagon, BP remained 80's/30's with a pulse of $60 \mathrm{bpm}$. Initial ICU laboratory variables showed ionized calcium of $4.4 \mathrm{mg} / \mathrm{dL}$, potassium of $3.4 \mathrm{mmol} / \mathrm{L}$, lactate of $2.72 \mathrm{mmol} / \mathrm{L}$, glucose of $127 \mathrm{mg} / \mathrm{dL}$, and $\mathrm{pH}$ of 7.27 . She was intubated due to hypoxia secondary to pulmonary edema. Eight hours after ICU admission, she developed frequent prolonged sinus pauses requiring transvenous pacing via a pulmonary artery catheter. She continued to worsen with profound metabolic acidosis requiring continuous venovenous hemofiltration. Charcoal hemoperfusion and albumin dialysis were unavailable for use in this case. Her circulatory collapse was unresponsive to vasopressors and thus two doses of methylene blue ( $2 \mathrm{mg} / \mathrm{kg}$ each) were attempted without a sustained effect. Therefore, she underwent emergent placement of right atrial (40 Fr Medtronic DLP malleable single stage venous cannula, http://www.medtronic.com/) and ascending aorta cannulae (Medtronic EOPA aortic $22 \mathrm{Fr}$ cannula) for initiation of central veno-arterial (VA) ECMO 13 hours from ICU admission (25 hours after reported ingestion; Table 1). The ECMO circuit was the Cardiohelp device with the HLS Module Advanced 7.0 Bioline heparin-coated portable cardiopulmonary support system (http://www.cardiohelp-us.com/en/home/). The ECMO circuit was primed with $600 \mathrm{cc}$ of Plasmalyte and $1000 \mathrm{U}$ heparin. She was supported for a total of 190 hours.

Peak diltiazem serum concentration was $13150 \mathrm{ng} / \mathrm{mL}$ (Figure 1; therapeutic range 100-200 ng/mL; diltiazem concentrations determined with High Performance Liquid Chromatography with Ultraviolet Detection; MEDTOX Scientific, Inc., St. Paul, MN). Desacetyldiltiazem concentrations were not available. Seventy-one hours after ingestion, the diltiazem level decreased to $2020 \mathrm{ng} / \mathrm{mL}$. To confirm downtrend, a diltiazem level 4 days after ingestion was obtained and found to have paradoxically increased to $6340 \mathrm{ng} / \mathrm{mL}$.

Although she received full circulatory support with central V-A ECMO and high-dose vasopressors, she had an extremely low systemic vascular resistance and her course was complicated by global hypoperfusion including organ, limb, and tissue ischemia. She developed multifocal compartment syndrome, thrombocytopenia, uncontrolled gastrointestinal bleeding, and fulminant multiorgan failure leading to a transition to comfort care and death on ICU day 9.

\section{Discussion}

This report describes the course of a patient who experienced diltiazem SR poisoning and did not survive despite

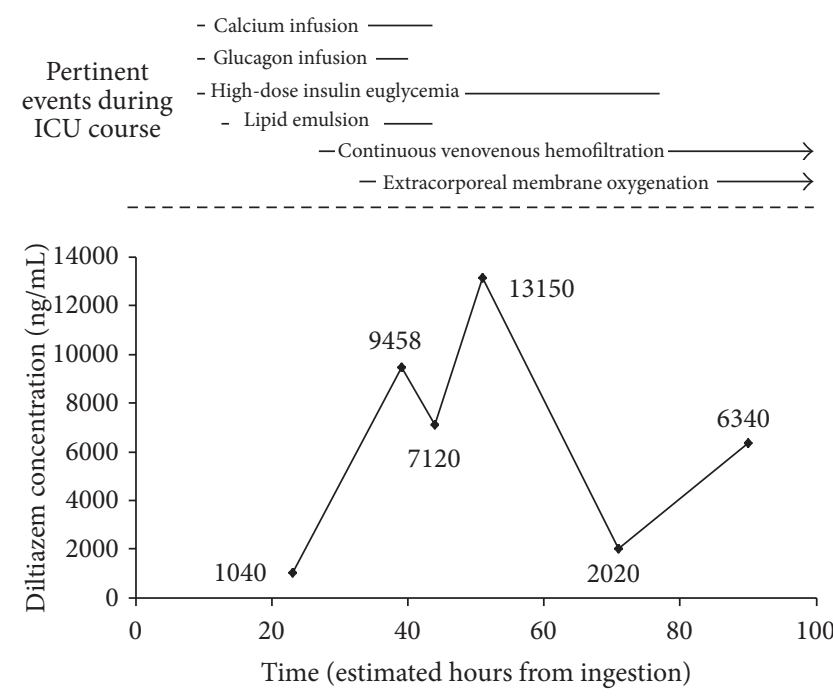

FIGURE 1: Diltiazem serum concentrations and concurrent interventions during ICU course according to suspected time from ingestion based on patient self-report.

maximal medical therapy, transvenous pacing, CVVH, and venoarterial ECMO. She developed profoundly elevated diltiazem serum concentrations and an inconsistent drug decay curve after this overdose. The peak concentration noted was approximately 100-fold greater than the therapeutic range $(100-200 \mathrm{ng} / \mathrm{mL})$ and is at the upper limit of what has previously been reported [4-6, 8-11]. No consistent diltiazem elimination rate occurred and levels remained significantly elevated to hour 90 of admission. We hypothesize that the unusually prolonged drug exposure and timing of ECMO initiation relative to the development of hepatic dysfunction may have been critical factors in the patient's outcome.

Although the evidence is limited, circulatory support with ECMO for nondihydropyridine CCB poisonings could theoretically preserve end-organ function and facilitate endogenous hepatic clearance of the drug. Indeed, in 62 critically ill poisoned patients, 12 of whom ingested verapamil or diltiazem, individuals who underwent extracorporeal life support had a significantly better survival than those who did not ( $86 \%$ versus $48 \%$, respectively; $P=0.02$ ) [12]. Three published reports describe the use of ECMO for sustained release nondihydropyridine $\mathrm{CCB}$ poisoning in pediatric/neonatal patients. In two patients, $\mathrm{CCB}$ poisoning was associated with verapamil in combination with the nonselective beta-blocker propranolol. ECMO cannulation occurred at 4 and 10 hours after intoxication and both patients survived to hospital discharge $[13,14]$. The third pediatric case reported is of a 16-year-old female with an acute intentional ingestion of 12 grams of sustained release diltiazem. She received gastric lavage, activated charcoal, and pacing. ECMO began 17 hours after the ingestion and at hour 22 she had evidence of mild hepatic dysfunction with peak AST and ALT of 320 and 197, respectively. After 48 hours of circulatory support, ECMO was terminated due to uncontrolled mediastinal hemorrhage, but the patient was able to survive to discharge [10]. Extracorporeal circulatory support 
has also infrequently been described in the setting of adult nondihydropyridine CCB intoxications [15-18]. A 41-yearold adult male intentionally ingested multiple medications including verapamil and was successfully managed with 5 hours of percutaneous cardiopulmonary bypass introduced 8 hours after the toxic ingestion [17]. Another case of a polyingestion which included $7.2 \mathrm{~g}$ of slow-release verapamil was initiated on ECMO in the emergency department and successfully managed with 6 days of support [15]. Lastly, over ten years at a single center, 17 patients with drug poisoning and shock were placed on extracorporeal life support. Four of these individuals ingested verapamil and received circulatory support within 5 hours of the ingestion. Ten (58\%) patients in the overall group developed cannulation-related injuries of the femoral vessels and 13 (76\%) patients survived. Two (50\%) of the 4 patients with verapamil ingestions survived [16].

Whereas several previous reports have signaled a possible benefit on outcomes with ECMO use for nondihydropyridine CCB poisonings, the patient in this case died despite maximal medical therapy, CVVH to control refractory acidosis and hyperkalemia, and circulatory support with ECMO. Multiple factors may have contributed to this negative clinical outcome. Her course was complicated by delayed mesenteric ischemia which, in the setting of poisonings, has been shown to affect younger patients with fewer risk factors [19]. The diltiazem concentrations seen in this patient were markedly elevated and erratic which suggests that the patient was exposed to sustained toxic levels for a longer period of time than in previous reports. Prior kinetic analyses of SR diltiazem overdoses have demonstrated an elimination halflife of 13-48 hours [5, 10, 11]. Zero order kinetics appear to predominate at concentrations $>650 \mathrm{ng} / \mathrm{mL}$ with a return to first order elimination below this threshold [6]. Durward and colleagues characterized serial diltiazem levels after overdose in a female patient who received 48 hours of ECMO. The admission diltiazem concentration was approximately $6000 \mathrm{ng} / \mathrm{mL}$. Two rounds of charcoal hemoperfusion were attempted which resulted in temporary reductions in serum diltiazem concentrations with near complete rebound in the 8 hours after each run. By hour 120 after ingestion, her diltiazem concentration was $<1000 \mathrm{ng} / \mathrm{mL}$ and she survived to be discharged from the hospital. In our case, stability of diltiazem elimination was not achieved and the serum concentration spontaneously rebounded from $2020 \mathrm{ng} / \mathrm{mL}$ at hour 71 after ingestion to $6340 \mathrm{ng} / \mathrm{mL}$ at hour 90 .

The atypical concentration pattern and prolonged exposure we found may have been affected by a number of factors. Diltiazem could have accumulated in the gastrointestinal tract because the patient did not receive gastric decontamination or because of the development of decreased mesenteric perfusion or an ileus. The bowel intervention for mesenteric ischemia may have contributed to the 90-hour rebound in serum concentrations (Table 1). We also cannot exclude the possibility that the $2020 \mathrm{ng} / \mathrm{mL}$ serum concentration drawn at 71 hours after ingestion was spurious. The timing of lipid exposure makes it unlikely that an altered volume of distribution associated with this therapy impacted drug levels, but alterations in protein binding may have resulted in heightened serum concentrations of free drug. CVVH has not been shown to significantly contribute to diltiazem elimination and thus it is unlikely that this concurrent intervention altered the serum levels [20].

In addition to the potential for altered drug absorption and distribution, we also hypothesize that the patient may have experienced altered diltiazem metabolism. It is of particular importance to preserve hepatic perfusion in the case of diltiazem poisonings because the drug undergoes extensive hepatic metabolism via deacetylation and only $1-3 \%$ of drug is eliminated unchanged in the urine [20]. Previous reports have either not described liver function at the time of ECMO initiation or demonstrated only mild increases in transaminases. In this case, ECMO began 17 hours from admission (25 hours from ingestion), but there was already significant AST and INR elevation in the absence of therapeutic anticoagulation, suggesting acute ischemic hepatopathy. Mechanical circulatory support to preserve hemodynamics and consequently endogenous drug clearance may have been insufficient to overcome this preexisting organ dysfunction. It is possible that introduction of ECMO prior to the onset of hepatic dysfunction may have resulted in improved perfusion and consequent drug clearance.

This case report of a SR diltiazem overdose describes drug toxicokinetics and the role for ECMO as a therapeutic intervention. We documented prolonged exposure to toxic diltiazem levels and an inconsistent drug decay curve, likely attributable to altered absorption, distribution, and metabolism. Although ECMO may theoretically facilitate endogenous diltiazem clearance, the timing of initiation may be a key determinant in its success. This patient exhibited signs of hepatic failure before ECMO initiation. This may have decreased the likelihood that enhanced circulatory support could facilitate sufficient endogenous drug clearance to offset the risks of the intervention. Future study is indicated to determine if early ECMO initiation in SR diltiazem overdoses improves patient outcomes.

\section{Conflict of Interests}

The authors declare that there is no conflict of interests regarding the publication of this paper.

\section{References}

[1] A. C. Bronstein, D. A. Spyker, L. R. Cantilena Jr., B. H. Rumack, and R. C. Dart, "2011 Annual report of the American Association of Poison Control Centers' National Poison Data System (NPDS): 29th Annual Report," Clinical toxicology, vol. 50, no. 10, pp. 911-1164, 2012.

[2] M. Deters, I. Bergmann, G. Enden et al., "Calcium channel antagonist exposures reported to the Poisons Information Center Erfurt," European Journal of Internal Medicine, vol. 22, no. 6, pp. 616-620, 2011.

[3] W. Kerns II, "Management of $\beta$-adrenergic blocker and calcium channel antagonist toxicity," Emergency Medicine Clinics of North America, vol. 25, no. 2, pp. 309-331, 2007.

[4] M. Belleflamme, P. Hantson, T. Gougnard et al., "Survival despite extremely high plasma diltiazem level in a case of acute poisoning treated by the molecular-adsorbent recirculating 
system," European Journal of Emergency Medicine, vol. 19, no. 1, pp. 59-61, 2012.

[5] D. M. Roberts, J. A. Roberts, R. J. Boots, R. Mason, and J. Lipman, "Lessons learnt in the pharmacokinetic analysis of the effect of haemoperfusion for acute overdose with sustainedrelease diltiazem," Anaesthesia, vol. 63, no. 7, pp. 714-718, 2008.

[6] K. M. Williamson and G. D. Dunham, "Plasma concentrations of diltiazem and desacetyldiltiazem in an overdose situation," Annals of Pharmacotherapy, vol. 30, no. 6, pp. 608-611, 1996.

[7] A. C. Young, L. I. Velez, and K. C. Kleinschmidt, "Intravenous fat emulsion therapy for intentional sustained-release verapamil overdose," Resuscitation, vol. 80, no. 5, pp. 591-593, 2009.

[8] R. E. Ferner, O. Odemuyiwa, A. B. Field, S. Walker, G. N. Volans, and D. N. Bateman, "Pharmacokinetics and toxic effects of diltiazem in massive overdose," Human Toxicology, vol. 8, no. 6, pp. 497-499, 1989.

[9] F. L. Cantrell and S. R. Williams, "Fatal unintentional overdose of diltiazem with antemortem and postmortem values," Clinical Toxicology, vol. 43, no. 6, pp. 587-588, 2005.

[10] A. Durward, A. M. Guerguerian, M. Lefebvre, and S. D. Shemie, "Massive diltiazem overdose treated with extracorporeal membrane oxygenation," Pediatric Critical Care Medicine, vol. 4, no. 3, pp. 372-376, 2003.

[11] K. Luomanmäki, E. Tiula, K. T. Kivistö, and P. J. Neuvonen, "Pharmacokinetics of diltiazem in massive overdose," Therapeutic Drug Monitoring, vol. 19, no. 2, pp. 240-242, 1997.

[12] R. Masson, V. Colas, J. Parienti et al., "A comparison of survival with and without extracorporeal life support treatment for severe poisoning due to drug intoxication," Resuscitation, vol. 83, no. 11, pp. 1413-1417, 2012.

[13] F. De Rita, L. Barozzi, G. Franchi, G. Faggian, A. Mazzucco, and G. B. Luciani, "Rescue extracorporeal life support for acute verapamil and propranolol toxicity in a neonate," Artificial Organs, vol. 35, no. 4, pp. 416-420, 2011.

[14] J. Kolcz, J. Pietrzyk, K. Januszewska, M. Procelewska, T. Mroczek, and E. Malec, "Extracorporeal life support in severe propranolol and verapamil intoxication," Journal of Intensive Care Medicine, vol. 22, no. 6, pp. 381-385, 2007.

[15] G. Maclaren, W. Butt, P. Cameron, A. Preovolos, R. McEgan, and S. Marasco, "Treatment of polypharmacy overdose with multimodality extracorporeal life support," Anaesthesia and Intensive Care, vol. 33, no. 1, pp. 120-123, 2005.

[16] C. Daubin, P. Lehoux, C. Ivascau et al., "Extracorporeal life support in severe drug intoxication: a retrospective cohort study of seventeen cases," Critical care (London, England), vol. 13, no. 4, p. R138, 2009.

[17] M. Holzer, F. Sterz, W. Schoerkhuber et al., "Successful resuscitation of a verapamil-intoxicated patient with percutaneous cardiopulmonary bypass," Critical Care Medicine, vol. 27, no. 12, pp. 2818-2823, 1999.

[18] W. G. Hendren, R. S. Schieber, and L. K. Garrettson, "Extracorporeal bypass for the treatment of verapamil poisoning," Annals of Emergency Medicine, vol. 18, no. 9, pp. 984-987, 1989.

[19] J. C. Nault, B. Megarbane, J. Theodore et al., "Poisoningrelated bowel infarction: characteristics and outcomes," Clinical Toxicology, vol. 47, no. 5, pp. 412-418, 2009.

[20] Diltiazem Full Prescribing Information, BTA Pharmaceuticals, Bridgewater, NJ, USA, 2010. 


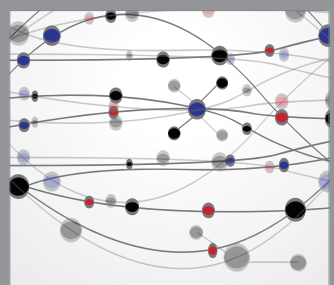

The Scientific World Journal
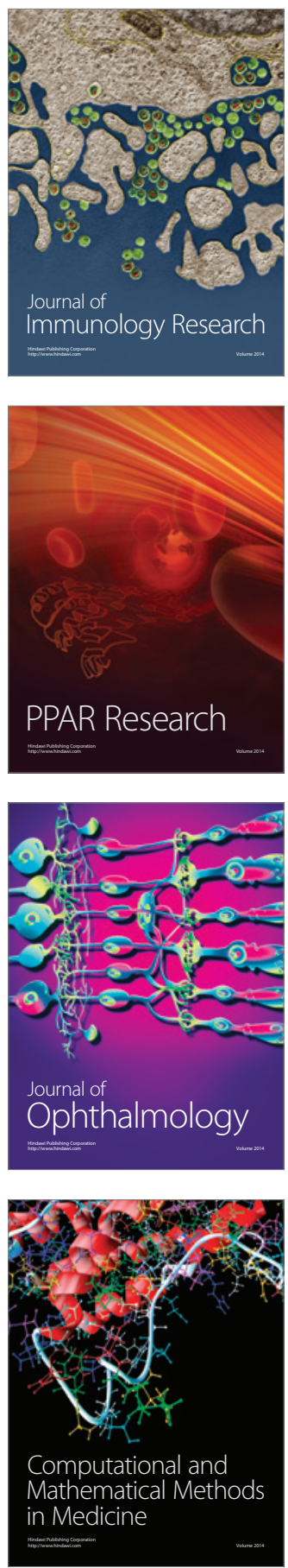

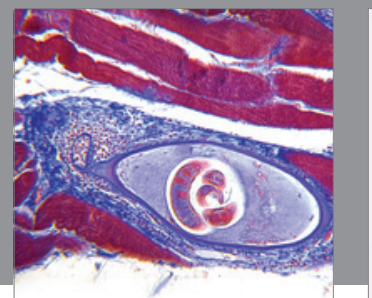

Gastroenterology

Research and Practice
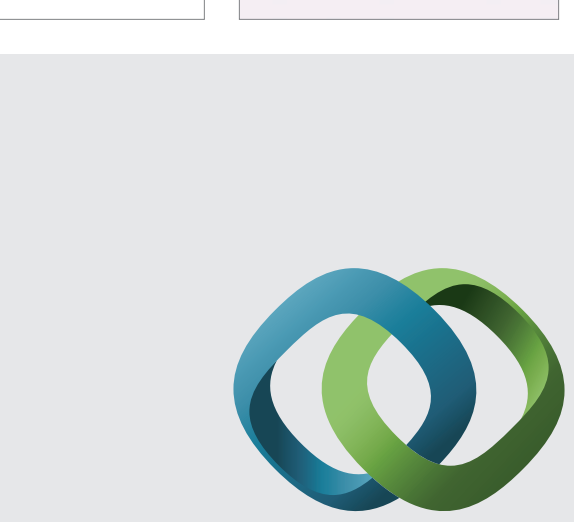

\section{Hindawi}

Submit your manuscripts at

http://www.hindawi.com
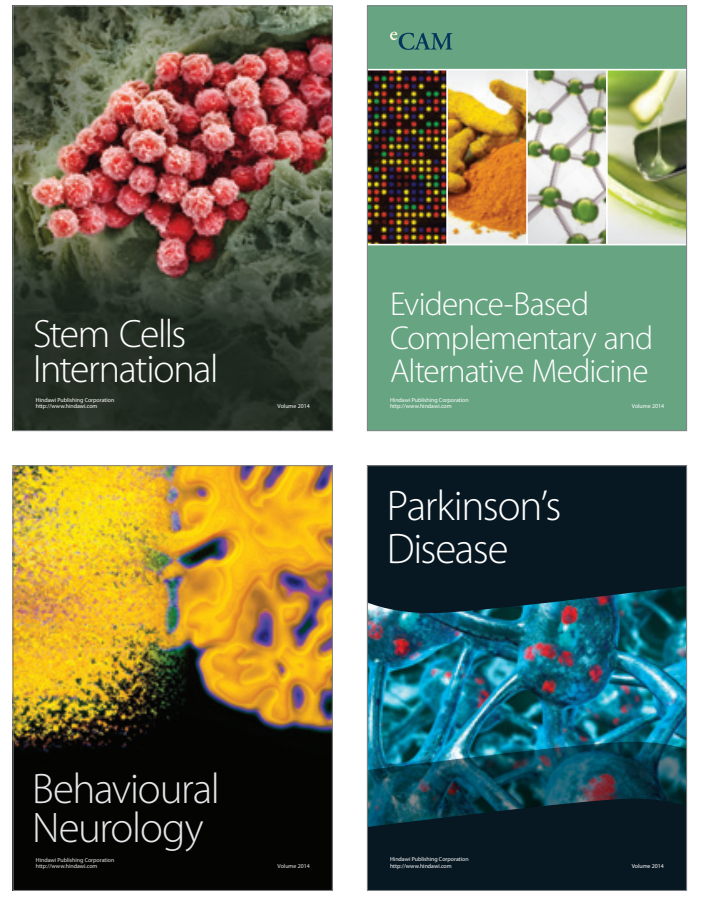
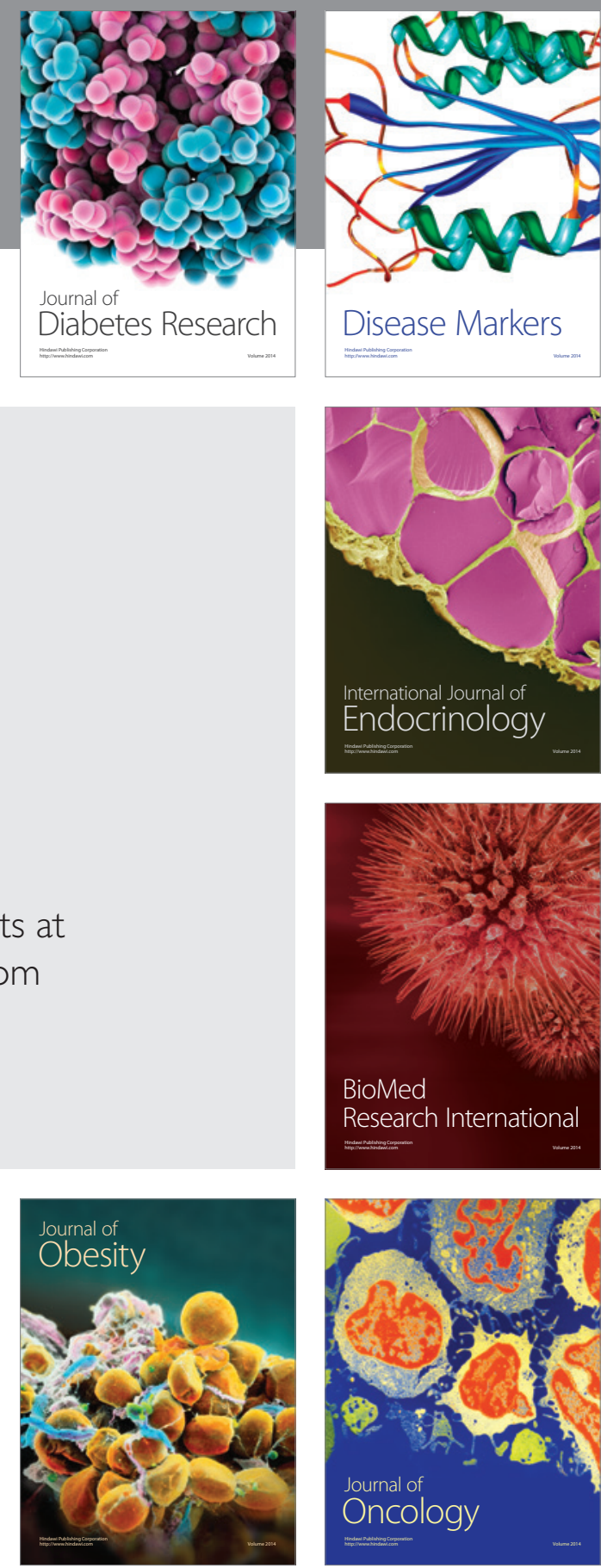

Disease Markers
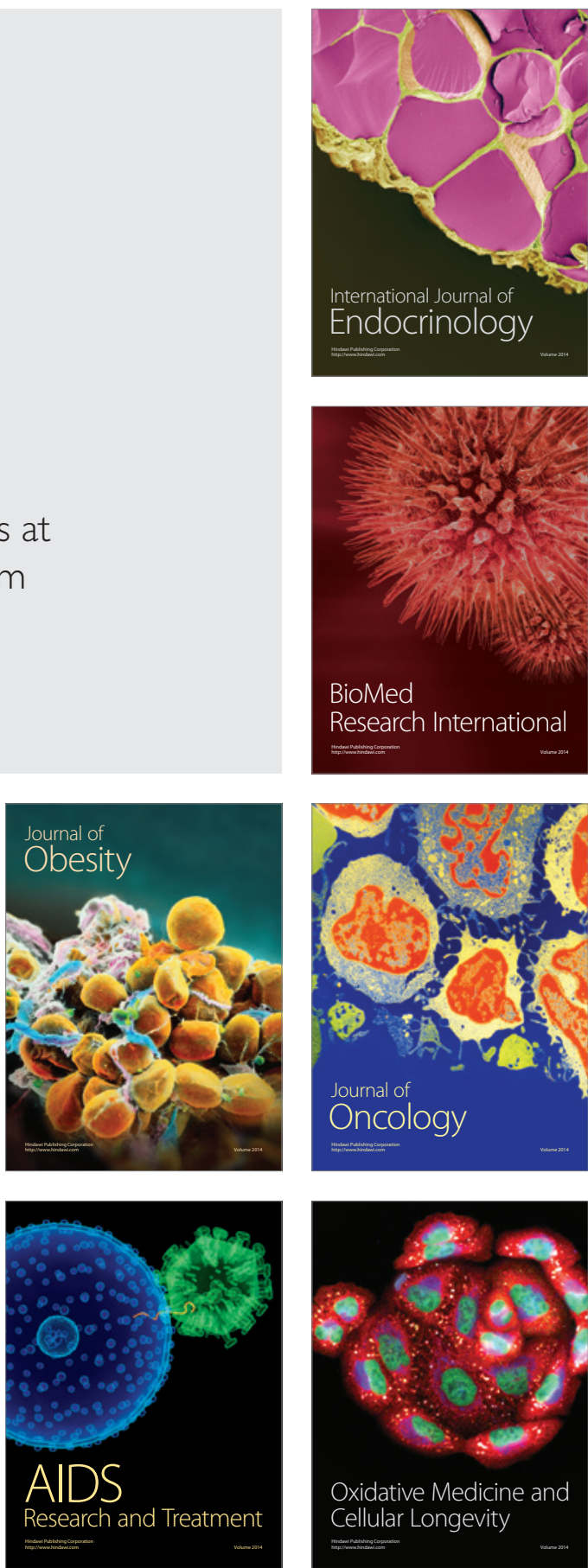